\title{
Greater Happiness for a Greater Number: Some Non-controversial Options for Governments
}

\author{
Jan Ott
}

Published online: 7 May 2010

(C) The Author(s) 2010. This article is published with open access at Springerlink.com

\begin{abstract}
There are dramatic differences in average happiness across nations ranging from 3.24 in Togo to 8.00 in Denmark on a 0-10-points scale. These differences are an indication that collective conditions in nations are important for happiness. Can governments play a role in the creation of such conditions? This question is addressed in an analysis of average happiness in 131 nations in 2006. The following sub-questions are considered. (1) Is there a positive correlation between average happiness in nations and the quality or the size of governments? (2) Can we explain a positive correlation in terms of causality? (3) Can we specify causality by discerning direct and indirect effects? (4) What about governments and inequality in happiness? (5) What can governments do to increase happiness intentionally? The conclusion is that the technical quality of governments is an important cause for average happiness in nations, and this causality can be specified to some extent. Good governments also reduce inequality of happiness in nations eventually. The implication is that governments can increase average happiness, and in due time reduce inequality in happiness, and that they have some non-controversial options to do so on purpose.
\end{abstract}

Keywords Happiness - Utilitarianism - Good governance - Democratic quality · Technical quality $\cdot$ Size of governments

\section{Introduction}

Utilitarians believe that governments should have the ambition to create the greatest happiness for the greatest number by legislation, jurisdiction and administration. This point of view raises two different questions: can governments increase happiness, and should they do so if they can. I try to answer the first empirical question, but the answers are relevant for discussions about the second ethical one. In the discussion, at the end of the last section, I make some personal remarks about a possible relationship between the two.

J. Ott (西)

Erasmus University Rotterdam, Rotterdam, The Netherlands

e-mail: jan.ott@planet.nl 
Many people are sceptical or even suspicious about governments, because they associate governments with bureaucracy, high taxes and inefficiency. Some of them can vividly report about government agencies making funny 'Kafkaesque' decisions, without adequate options to correct them. ${ }^{1}$ Since the break-down of communism there is more faith in free-markets as a source of well-being. The financial crises in 2008 made people more aware of the need to control and supervise markets, but did not boost their love for governments. Many people are unwilling to accept a strong or big government, always watching and acting as a 'big brother', because they are afraid they will lose their personal autonomy and freedom. But what can we conclude about the relationship between government and happiness, if we analyze the available data? In this contribution I will assess the potential importance of governments for happiness, but not by evaluating the impact of specific policies. I will do so by an evaluation of the relations between the quality and the size of governments and happiness. I discussed some aspects of these relations earlier in this Journal (Ott 2010a).

\subsection{Research questions}

1. How are the correlations between the quality and the size of governments and average happiness?

2. Are these correlations consequences of causality?

3. Can we specify a possible causal impact in terms of direct and indirect effects?

4. What about governments and inequality in happiness?

5. What can governments do to increase happiness intentionally?

\subsection{Plan of this paper}

I will discuss the concept of happiness first in Sect. 2, including its measurement and available data. The qualities and the size of government are discussed in Sects. 3 and 4. The answers to the research questions are presented in Sects. 5, 6, 7, 8 and 9, respectively. The conclusions are summarized and discussed in Sect. 10.

\section{Happiness in Nations}

\subsection{Concept}

Following Veenhoven (1984) I define happiness as 'the degree to which an individual judges the overall quality of his or her life-as-a-whole favourably'; in other words 'how much one likes the life one lives'. This is close to what Jeremy Bentham had in mind when he defined happiness as 'the sum of pleasures and pains' (Bentham 1780). ${ }^{2}$ Happiness, lifesatisfaction, personal utility, and subjective well-being are treated here as identical concepts, all referring to the subjective appreciation or enjoyment of life.

\footnotetext{
${ }^{1}$ One typical Dutch example: a civil servant is fired, even though everybody agrees he is an excellent worker. He wants to continue his work and there is a serious shortage of staff. He is fired because of his age. This is prohibited by law, but it was impossible nevertheless to redress this decision, made by the Dutch Ministry of Justice!

2 In Bentham's view such pleasures and pains are more than just simple positive or negative emotions. In chapter three of 'The principles of Morals and Legislation', 'of the four Sanctions or Sources of Pain and Pleasure', he discerns four origins of pleasures and pain: the physical, the political, the moral, and the religious. This is an indication that such emotions can derive from complex cognitive states of mind.
} 


\subsection{Measurement}

Since happiness is defined as something that an individual has in mind, it can be measured using questions. Many different questions are used; for an overview see the item bank in the World Database of Happiness (Veenhoven 2009a). The present analysis draws on responses to a survey question, developed by Cantril (1965), which reads as follows:

Suppose we say that the top of the ladder represents the best possible life for you and the bottom of the ladder represents the worst possible life for you. Where on this ladder do you feel you personally stand at the present time? Please use this card to help you with your answer.

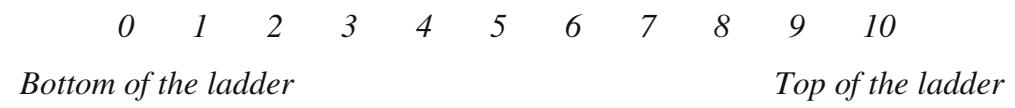

The formulation 'best and worst possible life' invites respondents to take into account all relevant domains of their life, like social relations, work, housing, leisure and so on. This question invites a comparative appraisal of life and measures the cognitive dimension of happiness in the first place. As such it is classified as an indicator of 'contentment' in the Item Bank of the World Database of Happiness.

\subsection{Data-source}

The question developed by Cantril has figured in many national surveys and has been used since 2006 in the Gallup World Polls. The samples used in these international studies, with usually around 1,000 respondents per nation but more for nations like India and China, are representative for the general population aged 15 and older. All findings gathered with this question, the Gallup-data included, are brought together in the collection 'Happiness in Nations' under item type 31 (Veenhoven 2009b). This analysis draws on that source and uses the available data for the year 2006 for 131 nations. I use the mean as an indicator for level of happiness (average) and the standard deviation (sd) as an indicator for inequality of happiness, since this is an appropriate measure for this concept (Kalmijn and Veenhoven 2005). A low standard deviation indicates low inequality; a high standard deviation indicates high inequality.

In recent years the supply of data has been growing steadily. Around 2000 data about happiness was available for 78 nations, in particular for relatively rich and developed nations. For the year 2006 there are data for 131 nations, not just rich nations but also relatively poor and less developed nations. Such changes, in the composition of the samples of nations to be analyzed, have consequences for the outcomes. One example is discussed in Sect. 8. There are 195 nations, so more data about happiness in more nations will be available in the future.

\subsection{Reliability and Validity of Self-reported Happiness}

The reliability and validity of self-reported happiness deserves some additional attention. The reliability of the individual answers on happiness-questions is limited. There is some instability in the answers and the answers are not invulnerable to contextual factors, like the sequence of the questions in the survey, the interviewer and the weather. Much of these 'random-errors' usually offset each other in the average happiness in nations.

The above-mentioned question on life-satisfaction has evident face validity; the question clearly addresses happiness as defined. Previous research has also shown high internal 
validity as expressed in consistency in responses to this question, when asked in different ways, such as in written questionnaires, face-to face interviews or interrogation by professional psychologists (Wessman and Ricks 1966; Oswald and Wu 2010). External validity appears in logical correlations with various factors that are likely to be related to happiness.

\subsection{Complications}

To answer happiness-questions people have to balance the good and bad things of their life. A positive answer does not exclude serious problems, and a negative answer does not exclude positive emotions about specific issues. This is not a problem in terms of reliability or validity, but the implication is that self-reported happiness is not always a comprehensive indicator for an individual or collective state of mind. Another complication is that people may be positive or negative about their lives without much justification in actual conditions. Individually or collectively they can be happy in bad conditions, because they expect a better life, or because their conditions are better than what they expected. They can also be unhappy in good conditions because they expect misery, or because their conditions are worse than expected. This is again not a problem in terms of reliability or validity, but the implication is that the relation between happiness and actual 'objective' conditions can be somewhat loose in specific situations.

\section{Quality of Governments in Nations}

\subsection{Concept}

I follow Helliwell and Huang (2008) and use the terms governance and government as equivalents. This is acceptable since both terms are very broad, including administration by governments and their legislation and jurisdiction.

The World Bank defines governance as follows: "governance consists of the traditions and institutions by which authority in a country is exercised. This includes the process by which governments are selected, monitored and replaced; the capacity of the government to effectively formulate and implement sound policies; and the respect of citizens and the state for the institutions that govern economic and social interactions among them" (Kaufmann et al.; World Bank June 2008, p. 7). The following aspects of good governance are discerned (ibid. pp. 7-8).

Voice and Accountability: the extent to which a country's citizens are able to participate in selecting their government, as well as freedom of expression, freedom of association, and a free media.

Political Stability and Absence of Violence: perceptions of the likelihood that the government will be destabilized or overthrown by unconstitutional or violent means, including domestic violence and terrorism.

Government Effectiveness: the quality of public services, the quality of the civil service and the degree of its independence from political pressures, the quality of policy formulation and implementation, and the credibility of the government's commitment to such policies.

Regulatory Quality: the ability of the government to formulate and implement sound policies and regulations that permits and promotes private sector development.

Rule of Law: the extent to which agents have confidence in and abide by the rules of society, and in particular the quality of contract enforcement, the police, and the courts, as well as the likelihood of crime and violence. 
Table 1 Correlations between government indicators around 138 nations, data-source: World Bank 2006

\begin{tabular}{|c|c|c|c|c|c|}
\hline & Voice + Acc. & $\begin{array}{l}\text { Political } \\
\text { stability }\end{array}$ & $\begin{array}{l}\text { Gov. } \\
\text { effective }\end{array}$ & $\begin{array}{l}\text { Regulatory } \\
\text { quality }\end{array}$ & $\begin{array}{l}\text { Rule of } \\
\text { law }\end{array}$ \\
\hline Voice + accountability & $\mathrm{X}$ & & & & \\
\hline Political stability & 0.69 & $\mathrm{X}$ & & & \\
\hline Government effectiveness & 0.81 & 0.77 & $\mathrm{X}$ & & \\
\hline Regulatory quality & 0.85 & 0.75 & 0.95 & $\mathrm{X}$ & \\
\hline Rule of law & 0.80 & 0.78 & 0.97 & 0.94 & $\mathrm{X}$ \\
\hline Control of corruption & 0.79 & 0.77 & 0.96 & 0.91 & 0.98 \\
\hline
\end{tabular}

All correlations in this Table and in the next Tables are based on a pair-wise comparison of variables. The correlations are comparable because they are still related to practically the same sets of nations. I do not report the significance. Significance is the chance that the correlation observed in the sample does not correspond with the correlation in the population from which the sample was drawn. My set of nations is not a random sample of all nations; nations were included if the required data was available

Control of Corruption: the extent to which public power is exercised for private gain, including both petty and grand forms of corruption, as well as 'capture' of the state by elites and private interests.

The six aspects of governance are all highly correlated, but the correlations between the first two, and between the first two and the last four, are somewhat lower (see Table 1). There is also a conceptual difference: the first two have to do with the political situation and the remaining four have to do with the institutional quality and effectiveness. I follow Helliwell and Huang (2008) who discern these types of quality and call them GovDem (average of the first two) and GovDo (average of the last four). I will call them democratic and technical quality. The correlations between the four components of the technical quality are always very high ( $>0.90$ for 2006), which is an indication that we are dealing with one consistent concept. The correlation between the two components of democratic quality is relatively low (0.69 in 2006). In general political stability goes together with a good score for voice and accountability, but stability can also be the outcome of repression without much voice and accountability. Democratic quality as a concept is therefore less homogeneous than technical quality. It is an alternative to use 'voice and accountability' as a single indicator for democratic quality, but this approach does not produce substantially different results.

\subsection{Measurement}

To assess the above mentioned aspects of quality of governments the World Bank collects data from independent sources produced by different organizations. These data sources consist of surveys of firms and individuals, the assessments of commercial risk rating agencies, non-governmental organizations, and a number of multilateral aid agencies and other public sector organizations. ${ }^{3}$ For 2006 data were used from 33 different sources from 30 different organizations. ${ }^{4}$

\footnotetext{
${ }^{3}$ For a discussion see 'Governance Indicators: Where Are We, Where Should We Be Going?' by Daniel Kaufmann and Aart Kraay (Kaufmann et al. 2008).

4 The World Bank transforms this information into scores for each of the six sub-indicators with a mean of 0 and a standard deviation of 1 in the original sample of 212 nations and regions (standardized $\mathrm{z}$-scores, approximately between -2.5 and +2.5 ; indicating relative positions in a specific year, in my sample in 2006).
} 


\subsection{Data-source}

All these data, background information included, is available at the site of the World Bank; Governance Matters VII: Aggregate and Individual Governance Indicators for 1996-2007; as published in 'World Bank Policy Research Working Paper 4654, June 2008' (Kaufmann et al.; World Bank 2008).

\section{Size of Governments in Nations}

\subsection{Concept}

The phrase 'size of government' suggests quantitative exactness, but this is misleading. It would be more realistic, but somewhat long winded, to use the more qualitative phrase 'the relative importance of the level of government activities in society'. This is usually what it is all about, and this is what I mean if I use the term 'size of governments'. This size of governments is about the level of all government activities taken together, and not just the level of specific activities, like military activities, social security, police, public health services, and so on. The popularity of this subject, whatever the phrase, is understandable. In every society we can make a distinction between horizontal and vertical relations between people or organizations (parties/agents). Horizontal relations are based on equality and free will, while vertical relations are based on hierarchy, power and authority. The typical juridical arrangement for horizontal relations is a contract based on consensus. For vertical relations it is an order, a legal decree, or a decision; in democratic nations eventually based on legislation, but not on consensus. The size of governments determines the relative importance of vertical relations in societies.

The distinction between horizontal and vertical relations is important because it runs parallel with the distinction between individual and collective responsibility. People have a clear and full individual responsibility in horizontal relations, but in vertical relations their responsibility is rather limited. The nature of this distinction also explains many negative feelings about governments: it is very difficult to defend yourself against misbehavior by governments; the juridical steps do so are usually complicated, expensive, long-winded, and very unpleasant. This background, plus the consequences in terms of regulation and taxation, explains the importance of the size of governments as a political issue.

\subsection{Measurement}

I will use Government Consumption as a percentage of total national consumption as an indicator for size. Government Expenditures, as a percentage of GDP, is a more comprehensive indicator for the financial importance of governments, but Government Consumption is more informative for the level of actual activities.

\subsection{Data-source}

Data about Government Consumption are obtained from the Fraser Institute (Gwartney and Lawson 2006). 
Table 2 Zero-order and partial correlations between qualities and size of governments and happiness in nations (around 125 nations)

\begin{tabular}{llllll}
\hline $\begin{array}{l}\text { Government } \\
\text { characteristics }\end{array}$ & Zero-order & $\begin{array}{l}\text { Control technical } \\
\text { quality }\end{array}$ & $\begin{array}{l}\text { Control democratic } \\
\text { quality }\end{array}$ & $\begin{array}{l}\text { Control size of } \\
\text { government }\end{array}$ & $\begin{array}{l}\text { Control } \\
\text { wealth }\end{array}$ \\
\hline Technical quality & +0.75 & $\mathrm{X}$ & +0.58 & +0.68 & +0.14 \\
Democratic quality & +0.61 & -0.17 & $\mathrm{X}$ & +0.50 & +0.04 \\
Size of government & +0.46 & +0.10 & +0.30 & $\mathrm{X}$ & +0.03 \\
\hline
\end{tabular}

Data-source: States of Nations (Veenhoven 2009c)

\section{Correlation Between Quality and Size of Governments and Average Happiness}

\subsection{Quality}

In previous research (Ott 2010a) with 127 nations I found high correlations between happiness, and democratic and technical quality, but higher for technical quality. Both correlations are independent of culture. The correlation between technical quality and happiness does not depend on wealth either, but the correlation between democratic quality and happiness is limited to relatively rich nations. I get the same results in my sample of 131 nations. Average happiness appears to be more connected with the technical quality than with democratic quality; the zero-sum correlations ${ }^{5}$ are +0.75 and +0.61 , respectively. The technical quality is apparently the most dominant quality, with higher and more autonomous correlations (see Table 2). For this reason I will concentrate on the relation between technical quality and happiness.

The relation between technical quality and average happiness is visible in Fig. 1. The relationship is clearly positive and quite strong. The relationship is apparently linear; there is no clear pattern of diminishing or increasing returns. Consequently a quadratic function does not fit the data substantially better than a linear one. ${ }^{6}$

In the right top section of Fig. 1 the correlation is higher than in the bottom left section, i.e. scores are closer to the fit-line. Nations seem to need some minimal level of technical competence when it comes to governance, before their quality can develop a substantial correlation with happiness. An additional explanation for the low correlations at the left sides is 'natural resources'. Some governments can collect and distribute a lot of money by the exploitation of natural resources. Even if their qualities are at a low level, they can still contribute to average happiness.

\subsection{Size}

As concluded in my previous research the relation between the quality of governments and happiness is independent of their size, while the relation between size and happiness depends fully on the quality. The zero-order correlation between quality $(+0.75)$ and happiness remains at a high level $(+0.68)$ if accounted for size, while the zero-order

\footnotetext{
5 A zero-order correlation is the correlation between two variables 'as such', without taking into account the effect of any other variable(s). A partial correlation measures the correlation between two variables with the effects of one (or more) variable(s), interaction effects included, controlled or removed.

6 A linear function explains $56 \%$ of the variance ( $R$ squared) in average happiness, a quadratic function $57 \%$.
} 




Fig. 1 Technical quality of governments and average happiness in nations in 2006

correlation between size and happiness $(+0.46)$ almost disappears (goes to +0.10$)$ if accounted for quality (Table 2).

\section{What About Causality?}

The correlation between happiness and the technical quality is high and rather independent of other factors. This is no surprise since the technical quality is defined and measured in a very broad way. In some respects the technical quality of governments is even comparable to the institutional quality in nations in general. Such a high correlation is however not necessarily a matter of any causal impact of technical quality on happiness. As explained in previous research (Ott 2010a) we can discern three possible explanations for the correlation between technical quality and happiness.

\subsection{Spurious Correlation?}

In this explanation, there is no causal relation between good technical governance and happiness, but both variables are dependent on a third variable. Wealth could be such a 
variable since it is likely to affect both happiness and the quality of government. Yet this cannot be the whole story since the correlations between technical quality and happiness does not completely disappear if the effect of wealth is accounted for first (Table 2). In addition to that good technical governance is important for wealth and wealth contributes to happiness. In other words: technical quality can have a causal impact on happiness in several ways, directly, and indirectly with intervening factors in between. Wealth is obviously a key-candidate to play such an intervening role (see next section).

\subsection{Causality: Impact of Happiness on Government Quality?}

In this explanation happiness affects quality of government rather than vice versa. Various effects can be involved: e.g. happy citizens being more apt to vote for investment in the public good, more willing to participate in government, and less apt to obstructive behavior. Such explanations fit the literature on benefits of happiness (Lyubomirsky et al. 2005; Guven 2009). Still, this is unlikely to be the whole story, for instance because government qualities have roots in historical developments, which were not always particularly happy. ${ }^{7}$

\subsection{Causality: Impact of Government Quality on Happiness?}

The last explanation is that better government makes happier citizens and this explanation appeals most to common sense. There must be some truth in this explanation, since alternative explanations are insufficient to explain the correlation completely.

\section{Specification of Causality: Direct and Indirect Effects}

The causal impact of technical quality on happiness can be explained in two ways. There can be a direct or an indirect impact. This distinction is similar to the distinction between 'procedural utility' and 'output utility', as developed by Frey and Stutzer (2005). Referring to Deci and Ryan (2000) they define procedural utility as “... the well-being gained from living and acting under institutionalized processes that also contribute to a positive sense of self and address the innate needs for autonomy, relatedness, and competence". The perceived fairness of procedures, and opportunities to participate, are important conditions for procedural utility. It obviously makes a difference if people can participate and are treated professionally, respectfully and carefully, and without too much bureaucracy and delay. Frey and Stutzer have shown that democratic quality has a direct impact on happiness, even if people dislike the outcomes of democratic procedures. We may assume however that technical quality, as determined by effectiveness, regulatory quality, rule of law and

\footnotetext{
7 Data about the quality of governments are considered as 'external' and are not explained. We may speculate however that the principle of the separation of three independent powers for legislation, administration and jurisdiction; provide for an explanation. This principle of the 'Trias Politica' was introduced by Montesquieu in 1748 before the American and French revolution. Since then this principle has had a positive impact on nation building and institutionalization in western nations. It has contributed directly to regulatory quality and rule of law, and, more indirectly, to political stability and control of corruption. In most other nations in the world the struggle against repression by some social class, or a colonial power, has been an alternative driver for nation building and institutionalization. In many nations this has eventually led to the formation of one political party with a very dominant position. In such nations the separation of powers is obviously problematic. Many nations are still in such situations, or in their aftermath.
} 
Table 3 Correlations between social-economic conditions and happiness in the second column, and between these conditions and technical quality of governments in the third column

\begin{tabular}{llll}
\hline Conditions & $\begin{array}{l}\text { Correlations with } \\
\text { average happiness }\end{array}$ & $\begin{array}{l}\text { Correlations with } \\
\text { technical quality }\end{array}$ & $\begin{array}{l}\text { Partial correlation technical } \\
\text { quality average happiness }\end{array}$ \\
\hline Wealth & +0.80 & +0.89 & +0.14 \\
Gender equality & +0.79 & +0.75 & +0.39 \\
Safety and health & +0.75 & +0.70 & +0.47 \\
Gross school enrollment-ratio & +0.73 & +0.70 & +0.49 \\
Economic freedom & +0.62 & +0.79 & +0.53 \\
Unemployment & -0.40 & -0.26 & +0.73 \\
Income-inequality (gini) & -0.29 & -0.41 & +0.72
\end{tabular}

In the last column the partial correlations between technical quality and happiness, after controlling for these conditions. Variables and data-sources described in the Appendix. Around 110 nations

control of corruption, are also important in direct contacts. In the context of rule of law adequate procedures are obviously indispensable to correct misbehavior by government agencies.

The indirect impact of quality, and of technical quality in particular, is probably also substantial. If governments are at an optimal quality-level they will be more effective in the realization of conditions that contribute to happiness. Such conditions can operate as intermediate or intervening factors between government and happiness. Some conditions are frequently put forward as important factors for average happiness.

In the second column of Table 3 the zero-order correlations are presented between average happiness and seven living conditions; and in the third column the zero-order correlations between technical quality and these conditions. These correlations are high for the first five conditions. In the last column the partial correlations are presented between technical quality and average happiness after controlling for these conditions. This is the usual test to assess the importance of intervening factors. The zero-order correlation of +0.75 , between technical quality and average happiness, goes down to $+0.14 ;+0.39$; $+0.47 ;+0.49$, and +0.53 if controlled for wealth, gender equality, safety and health, gross school-enrollment, and economic freedom. The implication is that wealth in particular is an important intervening variable between technical quality and average happiness, and the other four at a somewhat lower level. Unemployment and income-inequality are not very important as intervening variables, because the original correlation of 0.75 is not really reduced if controlled for these variables. This might be due to complications in the measurement of unemployment and income-inequality (see Appendix).

Combinations of the first five conditions can explain the differences in average happiness quite well. The explained variance in happiness goes up to $75 \%$, if all these conditions are used as independent variables in a linear regression to explain average happiness in nations. The importance of individual conditions 'in general' is however difficult to assess, because of their intensive interaction, resulting in high mutual correlations (statistical multicollinearity). ${ }^{8}$

\footnotetext{
${ }^{8}$ As a consequence (of this multicollinearity) it is not fruitful to apply more sophisticated statistical tests like path-analysis.
} 


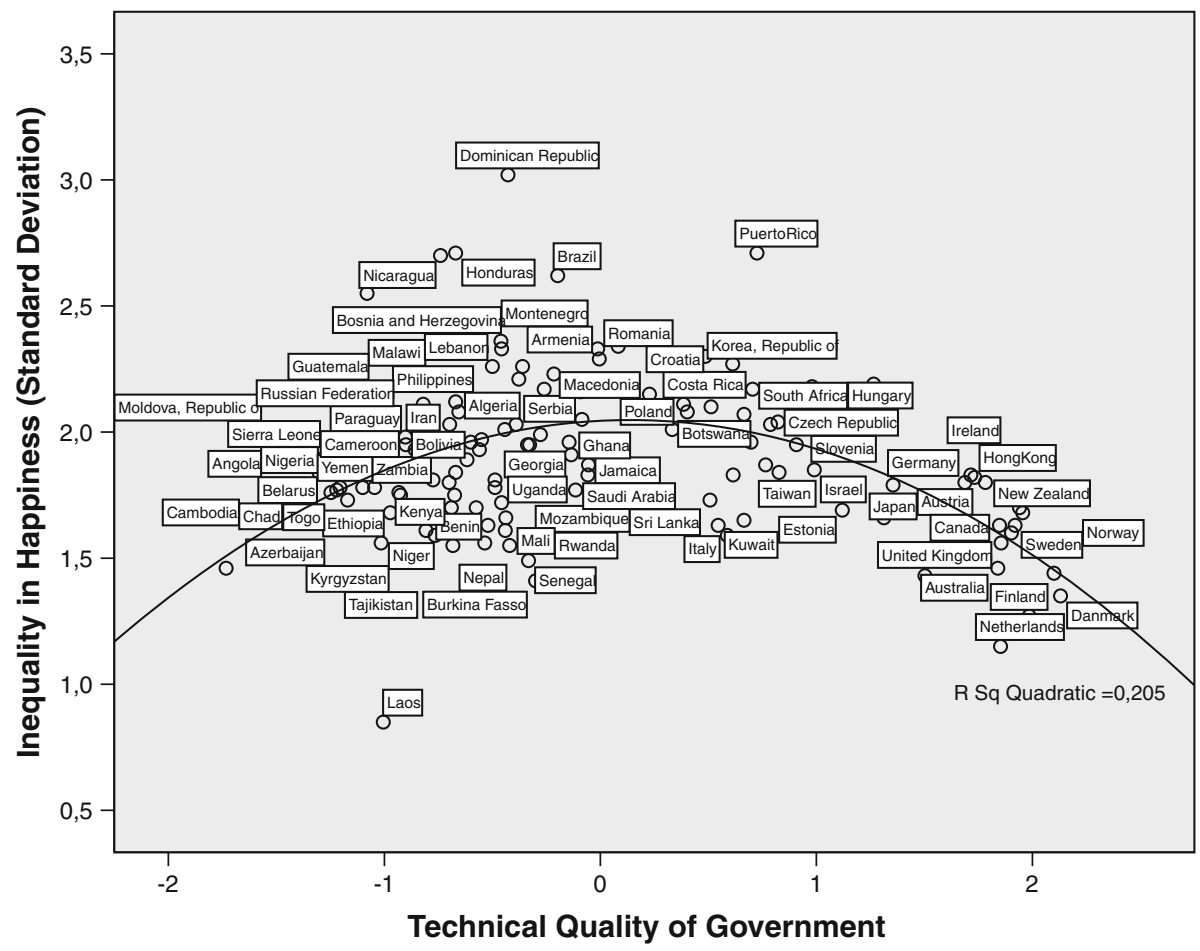

Fig. 2 Technical quality of governments and inequality in happiness in 2006

\section{Good Governance and Inequality in Happiness in Nations}

Increasing average happiness is a logical way to promote happiness for the greatest number, since there are no evident reasons to prioritize the happiness of specific groups. One traditional dilemma however is the relative importance of average happiness and inequality in happiness. In this section I will discuss the correlation between the technical quality of governments and inequality in happiness.

\subsection{Less Inequality with Technical Good Governance?}

In Fig. 2 we see the relationship between technical good governance and inequality in happiness as expressed in the standard deviation. There is a low negative correlation $(-0.18, N=128)$, suggesting that a higher technical quality goes together with less inequality. But this correlation is misleading because the relation is not linear. Inequality goes up first with higher technical quality and goes down if a certain level is reached ( $z$-score close to 0 , =average score in 2006). Consequently a quadratic function creates a better fit than a linear one. ${ }^{9}$ We see a positive correlation with

\footnotetext{
9 A linear function explains $3 \%$ of the variance ( $R$ squared) in the inequality of happiness, a quadratic function $21 \%$.
} 
inequality in happiness $(+0.29, N=78)$ for nations with a low level of technical quality $(z$-score $<0)$ and a substantial negative correlation with inequality in happiness $(-0.64, N=50)$ for nations with a high technical quality $(z$-score $>0)$. The correlation between democratic quality and inequality is similar, but at lower levels.

The causal impact of technical quality on happiness suggests an explanation for this relation between technical quality and inequality in happiness. If technical quality is at a low level, and the government starts to improve this quality and to develop some grip on happiness, there will be an increase in average happiness. But even if governments are not corrupt, some groups in society will benefit disproportionately, and there will be more inequality in happiness. If government quality goes up further, governments will be able to pay more attention to people who stay behind and will be more effective in creating collective conditions that contribute to happiness. Such conditions, e.g. in terms of public safety, healthcare and education, also reduce inequality in happiness by reducing the impact of income-inequality on the quality of life. This explanation is obviously interesting in ethical discussions about the promotion of average happiness and equality in happiness.

If we compare Figs. 1 and 2 we see that the conclusion of Ott in earlier research (2005), that there is in general a positive relation between average happiness and equality in happiness, is not replicated. This is clearly a consequence of a difference in the composition of the samples of nations that were analyzed. The sample Ott used for the years around 2000 consisted of 78 nations with relatively high levels of government qualities. The sample now used consists of 131 nations, including nations with relatively low levels of government qualities. In other words: the left side in Fig. 2 is 'quite new'.

\subsection{Size of Government and Inequality?}

We concluded in Sect. 5 that the relation between size of governments and average happiness depends on the qualities of governments, and in particular on technical quality. The same is true for the relation between the size of governments and inequality in happiness. This is very visible in Table 4: in the sample of nations with a low technical quality the correlation between size and inequality is very low but positive: bigger governments go together with more inequality. In the sample of nations with a high technical quality the correlations is substantially negative: bigger governments go together with less inequality.

Table 4 Correlations between size of government and inequality in happiness (standard deviation) for all nations, nations with a low government quality and nations with a high technical government quality number of nations in italics

\begin{tabular}{lll}
\hline All nations & Technical quality $<0$ & Technical quality $>0$ \\
\hline-0.23 & +0.02 & -0.46 \\
116 & 69 & 47 \\
\hline
\end{tabular}

Data-source: States of Nations (Veenhoven 2009c) 


\section{What Governments Can Do to Increase Average Happiness: Some Non-controversial Options}

The fact that the technical quality of governments has a substantial impact on happiness is important. The implication is that governments can increase happiness by improving their technical quality. This can be achieved by improving government effectiveness, regulatory quality, rule of law, and control of corruption. There are many options ${ }^{10}$ and the World Bank and other international organizations, like the UN, the IMF and the OECD, provide practical guidelines and support. Governments can select the best options after an inventory of their specific weaknesses and opportunities. This conclusion is interesting because the improvement of technical quality is usually not a controversial issue; most people will agree that improving the technical quality is perfectly all right, even if they have different political priorities otherwise. Improving the democratic quality or changing the size of governments will be more problematic and controversial, because such alternatives are more likely to have consequences for the distribution of power.

One additional non-controversial way to increase happiness is by carefully discerning three methods to assess happiness or subjective well-being.

1. Governments can analyze the behavior and the decisions of citizens, to find out what they want. In other words: they can observe their 'revealed preferences'. This is common practice in economics and leads to a high priority for economic growth. Unfortunately revealed preferences depend on the actual supply of goods and services, the knowledge and disposable budgets of consumers, the honesty of producers, and the transparency of markets in general.

2. Governments can analyze the 'stated preferences' of people, as they express them explicitly in inquiries, referenda, polls and elections. The weakness of stated preferences is that they also depend on the knowledge and imagination of respondents, and that they are not binding. People can say whatever they like without personal consequences.

3. Governments can analyze the conditions that make people happy, by comparing the conditions of people at different levels of happiness. People can adequately report about their own happiness, and this self-reported happiness is not directly dependent on their imagination, or on their knowledge of available products and services. A practical problem is the fact that happiness depends on many conditions, which makes it difficult to assess the importance of specific conditions. Happiness research requires a lot of data to reach meaningful conclusions, but the collection of this data is relatively easy and cheap.

10 Three more specific but interesting 'down-to-earth' options to improve the technical quality are:

a. the registration of property rights, in particular for real estate, i.e. have a land registry. As has been demonstrated by De Soto (2000) this is an important condition for economic development.

b. to register people, i.e. set up registrar's offices, as a necessary condition to organise adequate public education and health services.

c. to develop and implement general principles of good governance, to achieve decent and respectful relations between government institutions and citizens. This is really important because people can get very angry and upset by unfair government-decisions. Well-known examples of such principles are: carefulness and accuracy of decisions, respecting all interests, accounting for decisions, fair-play and equality (equal situations are treated equally), respect for reasonable expectations, no 'détournement de pouvoir' (powers have to be used in accordance with their legal background), proportionality (no disproportional consequences for citizens, relative to public interests). 
Most governments and political parties only use the first and second approach and neglect the third. Their assessments of happiness or subjective well-being are therefore unbalanced, and the measurement and analysis of self-reported happiness can help to overcome this problem (Ott 2010b). In addition to maximizing their technical quality, governments should therefore facilitate such efforts by stimulating the collection and analysis of happiness data. This would improve the assessments of subjective well-being, and such improved assessments would be valuable input for political debates and democratic decision-making.

\section{Conclusions and Discussion}

\subsection{Correlations}

The technical quality of governments is assessed by the average score of four government indicators, as measured by the World Bank: government effectiveness, regulatory quality, rule of law and control of corruption. It is a broad concept but the correlations between the four components are high. The democratic quality is assessed by the average score of two government indicators: voice and accountability and political stability. The correlation between these components is somewhat lower. Both qualities are in a positive way correlated with average happiness in nations, but the correlation between the technical quality and average happiness is the highest and the most independent. The qualities, and in particular the technical quality, are also important for inequality in happiness but in a different fashion. In a sample of nations with a low level of technical quality there is a positive correlation with inequality: more quality implies more inequality. Above a certain level, in 2006 a level close to the average, the correlation becomes substantially negative: more quality implies less inequality.

\subsection{Causality}

The correlations between technical quality and happiness are, at least to some extent, a consequence of causality. We can discern a direct and an indirect causality. The quality 'as such' is probably appreciated by citizens and creates 'procedural utility'. Quality also creates 'output utility', because better qualified governments are more effective in creating conditions that contribute to happiness. Such conditions can be perceived as intermediate or intervening factors between government qualities and happiness. The actual importance of such intermediate factors will be different in nations, and even in one nation it is difficult to assess the importance of individual conditions, because of their intensive interaction. Gender equality, wealth, economic freedom, education, and safety and health are examples of 'positive' intermediates.

\subsection{Causality and Inequality}

If technical quality is at a low level, and the government starts to improve this quality and to develop some grip on happiness, there will be an increase in average happiness. But even if governments are not corrupt, some groups in society will benefit disproportionately, 
and there will be more inequality in happiness. If government quality goes up further, governments will be able to pay more attention to people who stay behind and will be more effective in creating favourable collective conditions. Collective conditions, e.g. in terms of public safety, healthcare and education, contribute to equality in happiness, also by reducing the impact of income-inequality on the quality of life.

\subsection{Some Non-controversial Options to Increase Happiness}

Governments can increase happiness by improving their technical quality. They can do this by improving government effectiveness, regulatory quality, rule of law, and control of corruption. There are many options, and governments can select the best options after an inventory of their specific weaknesses and opportunities. This conclusion is interesting because the improvement of technical quality is usually not a controversial issue; most people will agree that improving the technical quality is perfectly all right, even if they have different political priorities otherwise. In addition to that governments can facilitate the collection and analysis of self-reported happiness data, to make the assessments of happiness, life satisfaction, utility, or subjective well-being, less dependent on revealed and stated preferences. Such improved assessments are valuable input for political debates and democratic decision-making.

\subsection{Discussion: Should Governments Increase Happiness?}

The conclusion that governments can increase happiness leads us to the next question: should governments increase happiness intentionally? In my view this is very acceptable in some respects. Happiness is measurable and widely appreciated in different cultures as a social value (Veenhoven 1984; Oswald and Wu 2010). Even if people focus not on happiness, but on other goals, they can still appreciate happiness as a positive 'by-product'. Happiness has also some appreciated consequences. It has a positive impact on health (Veenhoven 2008) and happy people are more willing to participate in government and are less apt to obstructive behavior (Guven 2009). And in research no serious structural tensions have been found between happiness and alternative values, like personal autonomy, justice, solidarity and freedom (Duncan 2010; Layard 2005, Diener and Seligman 2004). In my view governments should nevertheless primarily respect the personal autonomy of citizens, and as a consequence they should work within the context of democracy. I do not believe that governments should ever apply some general ideology as a substitute for democracy, or as an excuse for paternalism. The implication is that governments can always promote happiness directly by maintaining law and order and creating 'procedural utility', but, apart from that, they can only promote happiness intentionally, if they are entitled to do so by legitimate democratic decisions. In most nations it will be rather easy however, to achieve consensus about the non-controversial options just mentioned: improving the technical quality of the government and facilitating the collection and analysis of happiness data.

Open Access This article is distributed under the terms of the Creative Commons Attribution Noncommercial License which permits any noncommercial use, distribution, and reproduction in any medium, provided the original author(s) and source are credited. 


\section{Appendix: Additional Information About Variables Related to Social-Economic Living Conditions}

1. Wealth. Purchasing power parity per capita (in 2007-international dollars) (HDI 2006; UNDHP, HDR 2008).

2. Gender Equality as measured by the Gender Development Index (GDI 2007; UNDHP, HDR 2009).

3. The expected life-time at birth is used here as an indicator for objective safety and health, because there is no adequate alternative information available (HDI 2006; UNDHP, HDR 2008).

4. Gross School-Enrolment Ratio: \% of population in primary, secondary and tertiary education (HDI 2006; UNDHP, HDR 2008).

5. Economic freedom. The freedom to make economic decisions; average score of five aspects of economic freedom as measured by the Fraser Institute: size of governments, legal structure and security of property rights, access to sound money, freedom to trade internationally, regulation of credit, labor and business (Economic Freedom of the World, Fraser Institute 2006).

6. Unemployment (\% unemployed of labor force (CIA, The World Fact Book 2009, most data collected in the years 2002-2009)).

7. Income-equality. The Gini-index of the family-income distribution (CIA, The World Fact Book, 2009, most data collected in the years 2002-2009).

The measurement of the last two variables, unemployment and income-inequality, is complicated. In many nations there are extensive informal sectors, and it is difficult to collect economic-data for such sectors. On top of that there are substantial differences in the definitions of unemployment and income.

\section{References}

Bentham, J. (1780). The Principles of Morals and Legislation. Republished in 1988 by Prometheus Books, New York, USA.

Cantril, H. (1965). The Pattern of Human Concerns. New Brunswick, New York.

De Soto, H. (2000). The mystery of capital; why capitalism triumphs in the west and fails everywhere else. London: Bantam Press.

Deci, E. L., \& Ryan, R. M. (2000). The 'what' and 'why' of goal pursuits: Human needs and the selfdetermination of behavior. Psychological Inquiry, 11(4), 227-268.

Diener, E., \& Seligman, M. E. P. (2004). Beyond Money: Toward an economy of well-being. Psychological Science in the Public Interest, 5(1), 1-31.

Duncan, D. (2010). Should Happiness Maximization be the Goal of Government? Journal of Happiness Studies 11(2).

Frey, B. S., \& Stutzer, A. (2005). Beyond outcomes: Measuring procedural utility. Oxford: Economic Papers.

Guven, C. (2009). Are happier people better citizens? Economics Series SWP 2009/04, Deakin University Australia.

Gwartney, J. D., \& Lawson, R. A. (2006). Economic Freedom of the World. Annual report, Fraser Institute, 2006, Vancouver, Canada. Data available at: www.freetheworld.com/206/2006dataset.xls.

Helliwell, J., \& Huang, H. (2008). How's your government? International evidence linking good government and well-being. British Journal of Political Science, 38, 595-619. Cambridge University Press.

Kalmijn, W. M. \& Veenhoven, R. (2005). Measuring inequality in happiness in nations. In search for proper statistics. Journal of Happiness Studies 6(4).

Kaufmann, D., Kraay, A., \& Mastruzzi, M. (2008). Governance Matters VII: Aggregate and Individual Governance Indicators, 1996- 2007'. World Bank Policy Research Working Paper No. 4654, World Bank 2008. Data available at: www.govindicators.org. 
Layard, R. (2005). Happiness: Lessons from a new science. New York: Penguin.

Lyubomirsky, S., Diener, E., \& King, L. (2005). The benefits of frequent positive affect: Does happiness lead to success? Psychological Bulletin, 131, 803-855.

Oswald, A.J., \& Wu, S. (2010). Objective confirmation of subjective measures of human well-being: Evidence from the USA. Science 327.

Ott, J.C. (2005). Level and equality of happiness in nations: Does greater happiness of a greater number imply greater inequality in happiness? Journal of Happiness Studies 6(4).

Ott, J.C. (2010a). Good governance and happiness in nations, technical quality precedes democracy and quality beats size. Journal of Happiness Studies 11(3).

Ott, J.C. (2010b). Happiness, economics and public policy, a critique review article on 'Happiness, Economics and Public Policy' by Helen Johns and Paul Ormerod. Journal of Happiness Studies 11(1).

Veenhoven, R. (1984). Conditions of happiness. Dordrecht: Kluwer.

Veenhoven, R. (2008). Healthy happiness: Effects of happiness on physical health and the consequences for preventive healthcare. Journal of Happiness Studies 9(3).

Veenhoven, R. (2009a). Measures of happiness(Item bank). World Database of Happiness, Erasmus University Rotterdam. Assessed October 2009 from http://www.worlddatabaseofhappiness.eur.nl/ hap_quer/hqi.htm.

Veenhoven, R. (2009b). Happiness in nations. World database of happiness, Erasmus University Rotterdam. Assessed October 2009 from http://www.worlddatabaseofhappiness.eur.nl/nat_hap/nat_fp.php.

Veenhoven, R. (2009c). States of nations; Dataset for the cross national analysis of happiness World Database of Happiness, Erasmus University Rotterdam. http://worlddatabaseofhappiness.eur.nl/ statnat/statnat_fp.htm.

Wessman, A. E., \& Ricks, D. F. (1966). Winn, a case study of a happy man. Journal of Humanistic Psychology, 6(1), 2-16. 